\title{
CERTIFICAÇÃO DE MAÇÃS: UM ESTUDO SOBRE CONSUMO E CONVENÇÕES
}

\author{
Eduardo Rodrigues Sanguinet ${ }^{1}$ \\ Leonardo Xavier da Silva ${ }^{2}$
}

\begin{abstract}
RESUMO
O artigo analisa a percepção do consumidor em relação aos processos de certificação e de qualidade de maçãs no momento da compra. Os atributos de qualidade e de comportamento do consumidor são discutidos com base na Economia das Convenções. Procedeu-se com uma pesquisa de campo em quatro redes supermercadistas do município de Santa Maria (Rio Grande do Sul, Brasil), para obter informações sobre o nível de conhecimento dos consumidores sobre certificação e aos atributos considerados relevantes no momento da compra. Os resultados mostram que os consumidores não primam por questões relacionadas à certificação no ato da compra de maçãs e classificam seu nível de conhecimento como baixo. Concluiu-se que as informações conhecidas sobre certificação e demais características da maçã são menos relevantes para a realidade consumidora estudada, comparada a aspectos de mercado, como o preço.
\end{abstract}

Palavras-chave: certificação, maçãs, consumidor, qualidade, convenções.

\section{APPLE'S CERTIFICATION: A STUDY ABOUT CONSUMPTION AND CONVENTIONS}

\section{ABSTRACT}

This article analyzes the perception of the consumer regarding the processes of certification and quality of apples at the time of purchase. Quality attributes and consumer's behavior are discussed based on the Economic of Conventions. A field survey was carried out in four supermarkets in the city of Santa Maria (Rio Grande do Sul, Brazil) to obtain information on the level of consumer knowledge about certification and the attributes considered as relevant at the moment of purchase. The results show that consumers do not prioritize at issues related to certification in the purchase of apples and classify their level of knowledge as low. It was concluded that the known information about certification and other characteristics of the apple are less relevant to the consumer reality studied, if compared to market aspects, such as price.

Keywords: Certification. Apples. Consumer. Quality. Conventions.

\footnotetext{
${ }^{1}$ Graduado em Ciências Econômicas (UFSM). Mestrado em Desenvolvimento Rural (UFRGS). Doutorando em Economia do Desenvolvimento (PUCRS) e em Economia Aplicada com Menção em Estudos Regionais (UCN). E-mail: eduardorodriguessanguinet@gmail.com

${ }^{2}$ Graduado em Ciências Econômicas (UFRGS). Mestrado em Economia (UFRGS). Doutorado em Economia (UFRGS). Professor Adjunto do Departamento de Economia e Relações Internacionais (UFRGS). E-mail: leonardo.xavier@ufrgs.br
} 


\section{INTRODUÇÃO}

A produção de maçãs no Brasil foi condicionada a um conjunto de exigências relacionadas aos processos de segurança e qualidade da produção, principalmente a partir dos anos 1990 (ALPHANDÉRY ET AL, 2012). As normas de qualidade internacionais tornam-se cada vez mais relevantes para a comercialização de alimentos, estabelecendo padrões de equivalência e qualidade para os produtos transacionados a nível mundial. Os países europeus foram os primeiros que passaram a exigir maiores garantias sobre determinados padrões produtivos para a importação da fruta e outros gêneros alimentícios (ALLAIRE; BOYER, 1995; PERETTI; ARAÚJO, 2010).

Os sistemas de certificação são mecanismos que buscam assegurar a determinados produtos e processos produtivos garantias em termos de proteção ambiental, saúde e segurança do trabalhador, sanidade e armazenamento e transporte adequados. (BÄCKSTRAND, 2006; WILKINSON, 2007; HENSON; JAFFEE, 2007; FORNASIER, 2010). A emergência do tema da qualidade alimentar, em um contexto de complexa competitividade dos mercados globalizados, promove discussões nas ciências sociais sobre modelos e novos conceitos que passaram a contribuir para a compreensão desse fenômeno (FOUILLEUX, 2012; GUÉNEAU, 2009). No contexto regional/local, a literatura nacional sobre certificação na produção de frutas enfatiza a perspectiva desde o lado da produção, como Dorr et al., (2010; COMUNELLO, (2013); e Ambrosini \& Oliveira (2017), evidenciando que mostram a necessidade de trazer à discussão os processos de certificação de origem atualmente em curso no Brasil e o aprofundamento da discussão conceitual em torno dos mesmos (DORR et al., 2010; COMUNELLO, 2013; AMBROSINI \& OLIVEIRA, 2017).

O objetivo deste artigo é analisar a perspectiva do consumidor diante da convenção de qualidade e segurança atribuída à certificação de maçãs no momento da compra. Adota-se o referencial teórico da Economia das Convenções (EC) para analisar os atributos intrínsecos da fruta considerados relevantes por parte do consumidor. Complementarmente, avaliam-se as características socioeconômicas dos consumidores, de forma a verificar sua relação para com o conhecimento e discernimento sobre qualidade, tendo como referência a certificação.

O estudo contribui à discussão analítica relacionada ao comportamento do consumidor, tendo como enfoque o setor agroalimentar. A EC encontra um campo fértil de aplicações da coordenação das operações diante dos sistemas agroalimentares e se adequa às demandas sociais do setor agroalimentar (ALLAIRE, 1995; MARESCOTTI, 2000): diversidade produtiva, a pluralidade da qualidade, a heterogeneidade das formas de trabalho e a valorização do território. Avaliar as percepções dos consumidores sobre os processos de certificação agroalimentar se torna relevante pois pode influenciar o processo decisório, contribuindo assim para a efetividade das legislações a serem implementadas e avanço na consideração de outros aportes teóricos e analíticos não ortodoxos aplicados aos mercados. A proposta do estudo não é discutir como os processos de certificação modificaram os padrões produtivos da maçã. $\mathrm{O}$ artigo analisa como o consumidor compreende os processos de certificação, sendo dado o fato de a certificação ser um indicativo de qualidade e as maçãs serem submetidas a um sistema de controle e de certificação institucionalizados no Brasil.

$O$ artigo estrutura-se em cinco seções, contando-se esta introdutória. A segunda seção apresenta o aporte teórico da Economia das Convenções aplicada aos sistemas agroalimentares. A terceira sintetiza os procedimentos metodológicos adotados, enquanto a quarta apresenta os resultados. A última mostra as considerações finais e reflexões a partir dos resultados obtidos. 


\section{ECONOMIA DAS CONVENÇÕES E OS SISTEMAS AGROALIMENTARES}

A EC posiciona-se na fronteira entre a microeconomia e a sociologia (Gomez, 1994) e diferencia-se da economia clássica ao recorrer a outros mecanismos de coordenação, além do preço, para explicar a difusão de um bem no mercado. A teoria busca explicar como a noção de qualidade existente nas relações sociais de mercado - considerando-se a construção social em torno do termo -, pode incitar o senso de qualidade aos bens por parte dos indivíduos. Desenvolvida nos anos 1980, a EC aporta contribuições importantes sobre aspectos qualitativos presentes no funcionamento dos mercados.

Com respeito às fragilidades da teoria econômica neoclássica, EymardDuvernay (1989), Sylvander (1995) e Caldentey e Gomez (1997) apresentam aspectos teóricos da EC, e assinalam que a difusão de um produto no mercado passa por uma série de negociações entre os atores, as quais não se reportam unicamente ao preço de troca, sendo antes o resultado de convenções em que participam produtores e consumidores. Os autores evidenciam um distanciamento dos mecanismos puros de mercado, dada a inserção de elementos que enfatizam funções relacionadas com a informação e a pluralidade de formas de convenção na vida econômica.

Em relação à definição da qualidade dos bens agroalimentares, os princípios básicos que suportam a teoria neoclássica passam a ser questionados (HODGSON, 1994). A importância das instituições na redução da incerteza sobre a qualidade dos alimentos passa a ser reconhecida por meio da instituição de normas, garantias, marcas e símbolos, e emerge a opinião de que a coordenação econômica não se assenta apenas no mercado e nos preços dos produtos. Por outro lado, o reconhecimento da diversidade dos bens, a incerteza sobre as suas qualidades e os problemas de assimetria da informação entre fornecedores e consumidores, implicam perturbações nos mecanismos da concorrência. Com isso, os mecanismos autorreguladores de mercado nem sempre funcionam quando está em causa a definição da qualidade dos bens (EYMARD-DUVERNAY, 1989).

No contexto do setor agroalimentar, as mudanças e sua complexidade característica têm sido marcadas pela incerteza sobre as qualidades dos produtos comercializados (SYLVANDER, 1995). A crescente industrialização e o aumento da diversidade e diferenciação dos produtos, associados a problemas de assimetria de informação, tornam a análise econômica clássica limitada quando confrontada com a definição de qualidade dos bens. Seguindo essa lógica, aumentam os sistemas de certificação e controle que definem a conformidade dos bens a determinadas normas e padrões, evitando ou reduzindo as possibilidades de fraude e oportunismo.

As dificuldades dos atores econômicos transacionarem não é relacionada unicamente a um problema de assimetria de informação (EYMARD-DUVERNAY, 1989; THÉVENOT, 1986). Trata-se de um problema de incertezas avaliativas associadas à existência de diferentes sistemas de julgamento. No marco teórico da EC, a qualidade não está imposta em termos de sinalização de mercado e da regulação de preços. A abordagem convencionalista coloca em causa a coordenação da economia pelo mercado (SYLVANDER, 1995) e integra a problemática da incerteza sobre a qualidade e a análise dos dispositivos institucionais pelos quais os atores se coordenam, admitindo que a qualidade seja definida de forma endógena, resultado de um processo de construção social. Desta forma, a coordenação das atividades econômicas e a construção da qualidade dos produtos baseiam-se na pluralidade de convenções de qualidade, exógenas às leis do mercado, que intervêm 
na regulação das relações comerciais. A Figura 1 mostra os principais aspectos convencionalistas vinculados à noção de qualidade.

Figura 1 - Qualidade e convenções.

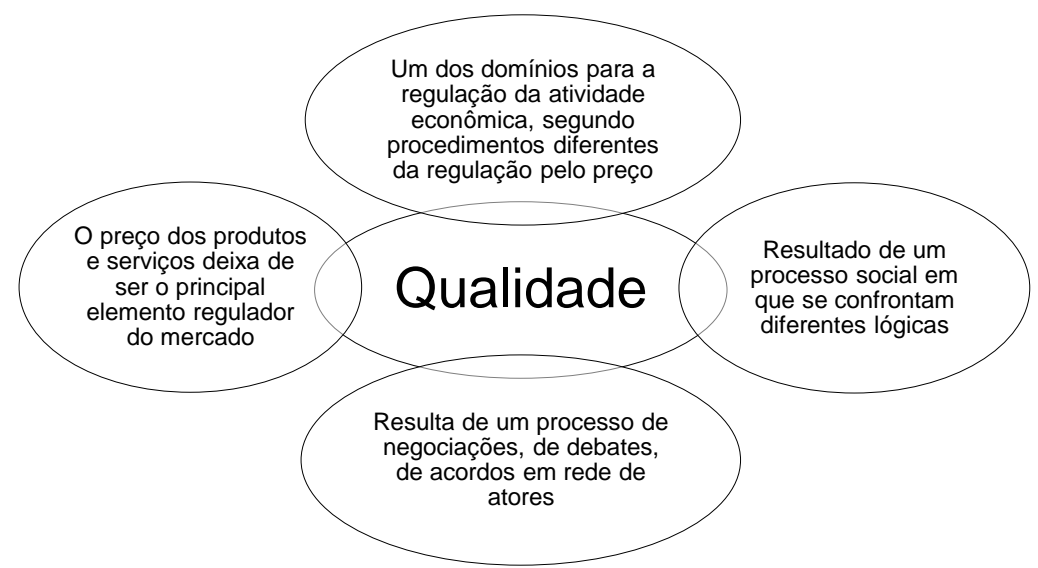

Fonte: Adaptado de Tibério e Conceição (2012).

A noção de padrão é vista através de convenção de qualidade. Devido à pluralidade, explora-se o problema da negociação da qualidade e a sua construção de padrões através de uma rede de atores. A qualidade agroalimentar implica o envolvimento de toda a cadeia produtiva e, quando relacionada a uma região em particular, associa-se à tradição e as características comuns do produto local (DE SAINTE-MARIE, 1995). Concebida como uma convenção social, a qualidade estabelece-se como o resultado de um acordo coletivo, por meio do qual os atores constroem dispositivos que permitem a construção de um entendimento comum frente a uma determinada cena de mercado. As regras, normas e padrões não emergem necessariamente para resolver falhas de mercado, o que limitaria o papel das instituições econômicas. Sequer as instituições são percebidas como simples constrangimentos da ação econômica. Para a EC, as instituições são imprescindíveis para viabilizar e potencializar o funcionamento dos mercados (NIEDERLE, 2013).

No referencial convencionalista, a coordenação é importante pois colabora para a compreensão do comportamento dos agentes econômicos. O entendimento das várias formas de coordenação é fundamental, uma vez que suas dinâmicas passam a ser determinantes para a atuação dos atores (THEVÉNOT, 2001). O universo das ações humanas permite fazer referência a várias concepções de um determinado bem. A coordenação, assim, baseia-se em caracterizações categóricas de seres humanos em termos de identidades, grupos de interesse, hábitos, etc. A pluralidade dos modos de coordenação é resultado da complexidade e do conflito, inerentes à própria ação cognitiva dos indivíduos.

A avaliação feita pelos agentes econômicos para um determinado bem se dá pelos princípios das ordens de valores, que nada mais são do que diferentes modos de coordenação. A pluralidade dos modos de avaliação justifica ações e posições frente aos produtos, ao mesmo tempo em que evidencia que os dispositivos de coordenação são eficazes e oferecem possibilidades de compromissos entre as diferentes ordens de valores (THEVÉNOT, 2001). A avaliação de decisões ou de ações é compreendida pelas diferentes ordens de valores pertinentes aos atores. Para 
Eymard-Duvernay (1989), as justificações para as ações são definidas pelas diversas ordens de valores, ou seja, pelas convenções. A EC, assim, identifica a existência de seis tipos de coordenação da ação dos atores (Quadro 1).

Quadro 1 - Formas de coordenação da ação convencionalista

\begin{tabular}{|c|c|c|c|c|}
\hline Fatores avaliativos & $\begin{array}{l}\text { Tipos de } \\
\text { informaçõe } \\
\text { s }\end{array}$ & $\begin{array}{l}\text { Objetos } \\
\text { qualificados }\end{array}$ & $\begin{array}{l}\text { Relações } \\
\text { construídas }\end{array}$ & $\begin{array}{l}\text { Qualificaçã } \\
\text { o humana }\end{array}$ \\
\hline \multicolumn{5}{|c|}{ Tipo 1 - Coordenação de Mercado } \\
\hline Preço & Monetária & $\begin{array}{l}\text { Produtos e } \\
\text { serviços }\end{array}$ & Troca & $\begin{array}{l}\text { Interessad } \\
0\end{array}$ \\
\hline \multicolumn{5}{|c|}{ Tipo 2 - Coordenação Industrial } \\
\hline Produtividade & $\begin{array}{l}\text { Mensuráve } \\
\text { is }\end{array}$ & $\begin{array}{l}\text { Investimento } \\
\text { s, técnicas e } \\
\text { métodos }\end{array}$ & $\begin{array}{l}\text { Funcionalidad } \\
\text { e }\end{array}$ & Profissiona \\
\hline \multicolumn{5}{|c|}{ Tipo 3 - Coordenação Doméstica } \\
\hline Fator reputação & Explicação & $\begin{array}{l}\text { Patrimônio e } \\
\text { ativos }\end{array}$ & Confiabilidade & Confiável \\
\hline \multicolumn{5}{|c|}{ Tipo 4 - Coordenação de Opinião } \\
\hline Fama & Semiótico & $\begin{array}{l}\text { Mídias e } \\
\text { marcas }\end{array}$ & Recognição & Famoso \\
\hline \multicolumn{5}{|c|}{ Tipo 5 - Coordenação Cívica } \\
\hline Interesse coletivo & Formal & Direitos & Solidariedade & $\begin{array}{l}\text { Represent } \\
\text { ativo }\end{array}$ \\
\hline \multicolumn{5}{|c|}{ Tipo 6 - Coordenação Inspirada } \\
\hline $\begin{array}{l}\text { Inovação e } \\
\text { criatividade }\end{array}$ & Emocional & Emoções & Paixão & Criativo \\
\hline
\end{tabular}

Fonte: Malafaia et. al. (2010).

Para a literatura convencionalista, os agentes são capazes de avaliar a qualidade dos bens com base em suas capacidades. Na coordenação de mercado, o fator preço é convencionado como forma de justificar suas ações, não carecendo assim de elementos adicionais. A ordem é concorrencial, enquanto a convenção é mercantil e baseada na troca. Na coordenação da forma industrial, a produtividade dos fatores é mensurada e planejada, e a qualidade passa a ser compreendida através das técnicas implementadas no processo produtivo. A ordem direciona-se para a noção de eficiência. A coordenação doméstica mantém forte relação entre a pessoalidade e proximidade dos atores, em que pese a confiança estabelecida nas transações. Nesta ordem, os atores negociam entre si os critérios de qualidade. $\mathrm{Na}$ coordenação de opinião, a qualidade de um bem é julgada pelas opiniões de outros e pela reputação dos operadores, em que estão as marcas e a mídia. A coordenação do tipo cívica é baseada na aderência dos agentes a um núcleo de princípios coletivos, em que os mesmos renunciam a sua própria individualidade, deliberando a qualidade tendo como referência os valores coletivos (SYLVANDER, 1995).

\section{NORMATIZAÇÃO DOS SISTEMAS AGROALIMENTARES E CERTIFICAÇÃO}

Os sistemas agroalimentares apresentam dinamismo relacionado às transformações e aos processos de regulação e intervenção direta (ALPHANDÉRY et al, 2012). O segmento passou a manter relação direta com a determinação de normas 
e regramentos específicos. A partir dos anos 1990, a atuação do Estado em muitos países passou a ser de intervenção mais direta nos mercados alimentares, com ações de cunho regulador. A mediação estatal das relações de consumo no mercado de alimentos e monitoramento da qualidade de produtos e serviços revela-se por meio de regulamentos técnicos ou ações fiscais a fim de preservar a saúde pública, privilegiando a institucionalização de normas e padrões que definem a qualificação dos alimentos (ALLAIRE; BOYER, 1995; PERETTI; ARAÚJO, 2010).

Diversos dispositivos de normatização se desenvolveram e passaram a produzir novas regras, mais normas, padrões, distintos selos, registros e atestados (FOUILLEUX, 2012; GUÉNEAU, 2009). No decorrer da década de 1990, observou-se a consolidação de formas privadas de regulação, as quais lançavam mão de inúmeras regras e padrões estabelecidos primeiramente pelas indústrias e, em seguida, pelo setor varejista, com vistas a forçar a readequação dos sistemas de produção agrícola e abastecimento alimentar.

Ao longo desse processo, têm se tornado cada vez mais reconhecidos os novos mecanismos de qualificação que traduzem a incorporação de diferentes referenciais de desenvolvimento para um sistema alimentar cada vez mais diversificado. Wilkinson (2007) caracteriza esse momento como o pontapé inicial para discussões acerca da normatização de processos produtivos e inovadores, que se expressavam em mercados emergentes como, para o caso dos agroalimentos, os orgânicos, o fair trade, as indicações geográficas, etc. No Brasil, tal intervenção se utiliza de indicadores para a realização de programas de monitoramento de produtos pela Agência Nacional de Vigilância Sanitária (ANVISA), órgãos estaduais e municipais e também pelo Instituto Nacional de Metrologia, Qualidade e Tecnologia (INMETRO). Esses processos de normatização e determinação de regras específicas a serem seguidas induziram a criação de órgãos privados reguladores, institucionalizando agentes a atuarem como certificadores.

A certificação é definida como um procedimento reconhecido oficialmente por organizações que denotam a alimentos e/ou a sistemas produtivos a conformidade em relação a certos requerimentos - padrões de qualidade (Codex Alimentarius, 2007). A exigência por produtos mais saudáveis e livres de agrotóxicos revelou tendências futuras para o Brasil, que se destaca na produção agroalimentar, na conquista de novos nichos de mercado: os produtos alimentares de alta qualidade e de produção controlada por mecanismos de certificação e com aval de autoridades públicas (BARROS; VARELLA, 2002).

Discute-se na literatura as controvérsias geradas pela certificação agroalimentar e, nesse sentido, Henson e Jaffee (2007) afirmam que há um grupo de estudiosos afirmando que a certificação é um propulsor necessário para exportar e proporcionar ao produtor oportunidades e acesso a mercados complexos. Outros autores, porém, argumentam que a certificação representa barreiras à entrada a países em desenvolvimento, que não existe price premium ${ }^{3}$ e que ocorre à marginalização e exclusão de produtores que não se adéquam a tal processo. Uma mudança particularmente importante no contexto atual diz respeito ao modo como o Estado atua no mercado alimentar, uma vez que os mecanismos de normatização foram inicialmente produzidos pelo poder governamental de forma unilateral para regular a ação do setor privado.

3 Prêmio de preço é a porcentagem em que o preço de venda de um determinado produto excede o preço de referência ou o preço médio do mercado. 


\section{ASPECTOS METODOLÓGICOS}

Para analisar os aspectos considerados relevantes pelos consumidores de maçãs no momento da compra, adotou-se o procedimento descritivo e estatístico. Os dados utilizados são de natureza primária e abrangem o município de Santa Maria, situado na região central do Rio Grande do Sul (Figura 3). A cidade é a mais populosa da região, apresentando uma área territorial de 1.788,121 km², contando com 261.031 habitantes no ano de 2010 (IBGE Cidades, 2018).

Figura 3 - Município de Santa Maria, Rio Grande do Sul, Brasil ${ }^{1}$
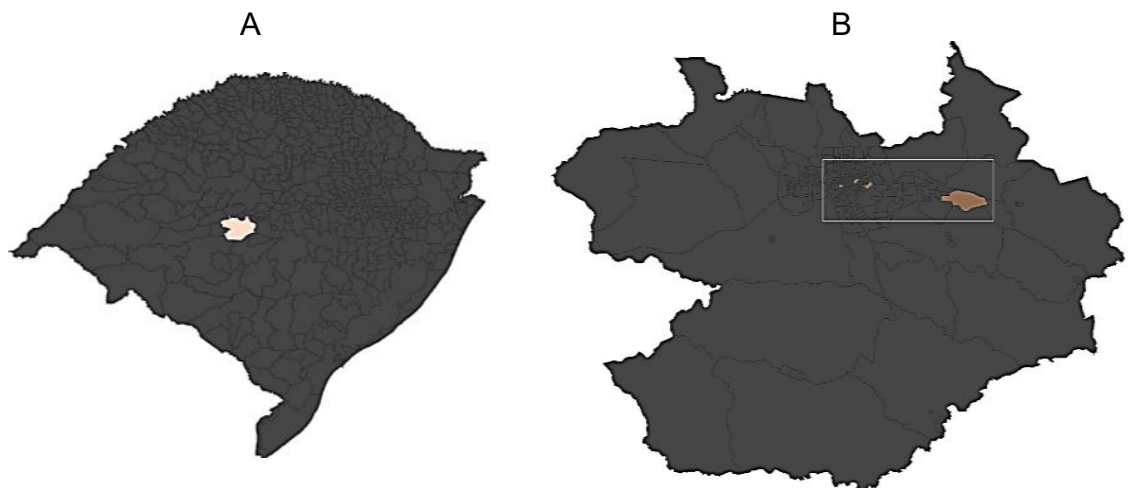

Nota: ${ }^{1}$ Na parte A está indicada a cidade de Santa Maria. Na parte B a localização das redes supermercadistas.

Fonte: Elaboração própria, 2019.

O público-alvo da pesquisa compreende esse universo de habitantes onde foi selecionada uma amostra, calculada de acordo com Barbetta (2008), a partir da amostragem aleatória simples (1):

$$
n=\frac{N \cdot\left(\frac{1}{E_{0}^{2}}\right)}{N+\left(\frac{1}{E_{0}^{2}}\right)} n=\frac{261031 \cdot\left(\frac{1}{(0,10)^{2}}\right)}{261031+\left(\frac{1}{(0,10)^{2}}\right)}=99,
$$

em que $n$ representa o tamanho mínimo da amostra calculada, $N$ o tamanho da população e $E_{0}^{2}$ é o do erro amostral tolerável e admitiu-se nível de $10 \%$. O valor de $N$ utilizado foi 261.031 habitantes (IBGE Cidades, 2018). A partir da aplicação do cálculo amostral, o número mínimo de formulários a serem aplicados foi de 99 . Foram aplicados ao todo 155 formulários, número acima do mínimo amostral, nas entradas dos estabelecimentos das quatro maiores redes supermercadistas presentes no município de Santa Maria - RS. Este critério levou em consideração a disponibilidade ofertada e a área física que o estabelecimento ocupa.

Os consumidores foram entrevistados de forma aleatória e sem qualquer sistematização, buscando-se identificar distintos perfis de consumidores de maçã em diversos períodos do dia, compreendendo o segundo semestre de 2014. Formularamse questões fechadas, agrupando informações gerais sobre o público, sobre o nível de conhecimento acerca dos processos de certificação, atrelado às questões sobre 
valoração e importâncias atribuídas sobre aspectos da fruta. As perguntas foram de cunho qualitativo e quantitativo, adotando-se escala do tipo likert (valores de um a cinco) e obtenção de valores brutos.

Para realizar comparações entre grupos de consumidores e os aspectos relacionados ao conhecimento sobre os processos de certificação da maçã, foram realizados testes de hipótese de acordo com a natureza da variável analisada, considerando-se o nível de significância estatística de 95\%. Para dados não pareados, utilizou-se o teste " $t$ " de Student. Este teste paramétrico permite comparar uma mesma variável em duas amostras diferentes, e em um determinado instante (BARBETTA, 2008). Foi empregado nas análises envolvendo variáveis quantitativas e com distribuição normal. O segundo teste aplicado foi o de Qui-Quadrado $\left(X^{2}\right)$ para independência. Uma das importantes aplicações de tal teste é quando se deseja verificar a associação ou dependência entre duas variáveis qualitativas. Os testes de hipótese foram aplicados para verificar se há diferenças entre o grupo de consumidores que sabe e os que não sabem o que é certificação quanto: (i) à importância dada ao selo de certificação; (ii) consideração do preço como aspecto preponderante no momento da compra e (iii) preferência apontada para comprar maçã com algum indicativo de certificação.

Os resultados da aplicação dos testes permitem a verificação de diferenças de comportamento e percepção dos grupos de consumidores que sabem daqueles que não sabem o que é certificação. Isso possibilitou a análise que relacionasse o fato de ter conhecimento sobre os processos de certificação com a forma como o consumidor se comporta ao acessar o mercado de maçãs e como atribui importância para a certificação.

\section{RESULTADOS E DISCUSSÕES}

\subsection{CARACTERÍSTICAS DA AMOSTRA}

A percepção de qualidade dos alimentos difere de indivíduo para indivíduo e pode variar de acordo com influências culturais características e sistemas socioeconômicos. O público consumidor de Santa Maria - RS analisado a partir de um recorte amostral mostra-se heterogêneo em termos de suas características socioeconômicas. Em linhas gerais, o perfil do consumidor de Santa Maria contou com a participação de todas as faixas de idade compreendidas entre 15 e 73 anos, com predominância de idades acima dos 37 anos. A amostra é constituída por $55 \%$ de mulheres e $45 \%$ de homens, e o estado civil do público consumidor está distribuído, quase que igualitariamente, entre casados e solteiros. O nível de escolaridade representado pela maior parte dos consumidores é superior completo ou incompleto, totalizando $39 \%$ dos participantes da pesquisa. Quanto à renda familiar, os valores médios superiores a $\mathrm{R} \$ 3.000,00^{4}$ mensais. Com base nessas características do público consumidor que compôs a amostra, as subseções seguintes apresentam a análise da percepção dos consumidores quanto aos aspectos pertinentes à certificação de maçãs.

\subsection{CONSUMO DE MAÇÃS EM SANTA MARIA}

O processo de compra de maçãs por parte do consumidor compreende a tomada de decisão dos indivíduos em gastar seus recursos (tempo, dinheiro e esforço) neste item de consumo. $O$ consumo de frutas vem aumentando nas preferências do

4 Em valores reais de 2018 . 
consumidor, fato que se reflete diretamente no aumento da produção: o Brasil é o terceiro maior produtor mundial, com uma produção anual de trinta e quatro milhões de toneladas (BARROS et al., 2007).

Para fins de comparação, de acordo com MAPA (2014), o consumo aparente ${ }^{5}$ de maçã no Brasil, em 2012, foi de 5,78 kg/habitante/ano. Países vizinhos do Brasil, como a Argentina, por exemplo, mantém consumo aparente de 13,4kg/hab/ano e o Chile com 9,9 kg/hab/ano. Os Estados Unidos e o Reino Unido mantêm o nível de consumo aparente de $24,2 \mathrm{~kg} / \mathrm{hab} / \mathrm{ano}$ e $27,8 \mathrm{~kg} / \mathrm{hab} / \mathrm{ano}$, respectivamente. Para a realidade brasileira, o consumo aparente médio é de menos de uma maçã por semana. Em Santa Maria, o número de maçãs consumidas semanalmente varia de nenhuma (mínimo) até vinte e cinco (máximo) e que os valores que representam um maior percentual de indivíduos são de duas, três e sete maçãs por semana, refletindo um consumo maior que a média nacional.

De acordo com IBGE (2010), destaca-se o consumo de maçã superior ao de outras frutas mais tradicionais como abacaxi e mamão no cenário nacional. Questões relativas à oferta desta fruta durante todo o ano, preços acessíveis, praticidade para o consumo individual e facilidade de acesso, são razões que podem ser apontadas para esse consumo (PEROSA et al., 2012). De forma a qualificar a discussão sobre a perspectiva do consumidor santa-mariense em relação à compra de maçãs, a Tabela 1 mostra os tipos de fruta preferidos no município.

Tabela 1 - Tipos de maçã consumidos em Santa Maria.

\begin{tabular}{llll}
\hline Tipo de maçã & Percentual (\%) & Tipo de maçã ${ }^{*}$ & Percentual (\%) \\
\hline Indiferente & 21,15 & Maçã Gala & 18,91 \\
Maça Nacional & 7,69 & Outros tipos & 2,56 \\
Maçã Argentina & 17,95 & Maçã Verde & 2,56 \\
Maçã Fugi & 29,18 & Total & 100 \\
\hline
\end{tabular}

* Os próprios consumidores apontaram os tipos preferidos da fruta. Esta pode ser uma primeira aproximação da relação entre a mensuração de qualidade e a análise do consumidor, uma vez permite verificar a forma como é feita a avaliação sobre diferentes possibilidades de compra de maçã.

Fonte: Elaboração própria, 2019.

A coordenação é baseada em caracterizações categóricas de seres humanos em termos de identidades, grupos de interesse, hábitos etc. A maioria dos consumidores santa-marienses mostra-se preferível ao tipo fugi e ao tipo argentina. A maçã do tipo verde é a menos preferida. Os resultados da confrontação de diferentes grupos sociais são de complexidade e de conflito, fatores inerentes à realidade e condição humana, o que resulta numa variedade de modos de coordenação. Para a realidade do mercado de maçãs analisado, destaca-se o percentual de indivíduos que se mostram indiferentes ao tipo de maçã a ser consumida. Isso pode relacionar-se ao não conhecimento quanto à variedade de tipos comercializados ou indiferença no momento da compra, em que podem se destacar outros fatores como preponderantes no momento da compra da fruta e que podem ser vistos como mecanismos de coordenação dos consumidores.

No momento da compra, o consumidor dispõe de diversas formas de avaliação que podem conduzir ou não para a compra desse bem. Os princípios de avaliação para a EC, chamados ordens de valores, constituem diferentes modos de

5 O consumo aparente é obtido pela soma da produção nacional com as importações, subtraída das exportações totais em um determinado período. 
coordenação. Isso se deve aos processos de qualificação das pessoas e das coisas (MARESCOTTI, 2000). Thevénot (2001) reconhece a existência de uma pluralidade de modos de avaliação que os agentes usam para justificar suas posições, o que pode ser válido para suas ações de compra. A pluralidade destaca os dispositivos de coordenação eficazes e oferecem possibilidades de compromissos entre as diferentes ordens de valores.

As especificidades dos produtos/serviços derivam da realização da variedade de convenções de coordenação entre os atores. Nessa lógica, a natureza dos produtos, ou seja, a sua qualidade, passa a ser definida não somente pelo mercado e tecnologias, mas também pelas convenções. Para aproximar a compreensão da avaliação dos atributos da fruta considerados mais importantes de acordo com o consumidor final no momento da compra de maçãs, a Tabela 2 retrata alguns aspectos e sua relação com a percepção do consumidor santa-mariense.

Tabela 2 - Atributos da fruta considerados no momento da compra

\begin{tabular}{|c|c|c|c|c|c|c|c|c|c|}
\hline Estatísticas* & $A$ & B & C & $\mathrm{D}$ & $E$ & $\mathrm{~F}$ & $\mathrm{G}$ & $\mathrm{H}$ & I \\
\hline Média & 4,43 & 3,8 & 3,38 & 3,85 & 4,28 & 3,82 & 4,02 & 4,05 & 2,56 \\
\hline Erro padrão & 0,07 & 0,1 & 0,11 & 0,1 & 0,09 & 0,1 & 0,1 & 0,09 & 0,13 \\
\hline Mediana & 5 & 4 & 4 & 4 & 5 & 4 & 4 & 4 & 2 \\
\hline $\begin{array}{l}\text { Desvio } \\
\text { padrão }\end{array}$ & 0,86 & 1,1 & 1,42 & 1,3 & 1,1 & 1,29 & 1,2 & 1,09 & 1,56 \\
\hline $\begin{array}{l}\text { Coeficiente } \\
\text { de variação }\end{array}$ & 0,19 & 0,3 & 0,42 & 0,34 & 0,26 & 0,34 & 0,3 & 0,27 & 0,61 \\
\hline
\end{tabular}

Dos nove atributos avaliados, os consumidores atribuíram níveis de relevância em escala de um a cinco - o nível um representa pouca relevância, enquanto o nível cinco representa muita relevância. Esses atributos constituem-se de elementos perceptíveis de senso comum no momento da compra de maçãs. De acordo com a EC, a identificação da existência de justificativas para coordenar as ações dos atores sociais é entendida como ordem e relaciona-se a princípios de avaliação para a tomada de decisão. Com base nas informações dispostas na Tabela 2 , têm-se medidas estatísticas descritivas para os níveis atribuídos pelos consumidores, em que os mais próximos de cinco são aqueles em que o público consumidor atribui maior importância.

Nota-se que o tamanho, o conhecimento sobre o nível de agrotóxicos, a firmeza e a doçura da maçã são, respectivamente, os principais atributos considerados no momento da compra da fruta. É interessante observar que informações disponíveis sobre o nível de agrotóxicos mostram-se como relevantes para o consumidor. Diante das discussões acerca das boas práticas da produção de maçã, bem como dos processos mais amplos de certificação e qualidade, a temática do uso de agrotóxicos na produção é recorrente. Por outro lado, o consumidor possui nível baixo de relevância atribuída a respeito da obtenção de informações sobre procedência da fruta.

As convenções, enquanto características de um determinado bem que orientam a avaliação feita pelos atores sociais, são atributos naturais, sociais, culturais e econômicos que atuam através de imagens socialmente construídas, que tornam a 
identidade do produto reconhecível (NIEDERLE, 2013). O autor cita Schumpeter (1983, p. 183) para exemplificar essas nuances: "[...] uma coisa é bela porque ela agrada, ela não agrada porque ela é objetivamente bela". Ainda com base na Tabela 2 , os maiores desvios em relação à média, relacionados aos atributos da maçã, são relacionados à embalagem, procedência e suculência da fruta. Essa informação faz com que se empreenda que tais atributos, apesar de terem relevâncias altas apontadas, também apresentam as maiores variações quanto ao valor médio, ou seja, em relação ao que a maioria respondeu e/ou atribuiu em termos de nível de importância dos atributos supracitados.

Os coeficientes de variação indicam o quanto os atributos da maçã são avaliados de distintas formas por parte do público consumidor. $\mathrm{O}$ atributo embalagem apresenta o maior coeficiente, seguido pelos atributos procedência da fruta, variedade e maciez, retratando que esses são aqueles que mais apresentam variabilidade entre os níveis e, ao contrário, o tamanho é o que apresenta menor variação em níveis apontados pelos consumidores.

\subsection{CERTIFICAÇÃO E A VISÃO DO PÚBLICO CONSUMIDOR}

Os produtores de alimentos e as instituições reguladoras tentam restaurar a confiança dos consumidores por meio da aplicação de sistemas de rastreabilidade e certificação dos alimentos e ingredientes (VAN RIJSWIJK et al., 2008). É importante salientar que rastreabilidade só aumenta a confiança dos consumidores se eles estiverem conscientes e informados a respeito desse sistema, bem como da forma como ela é aplicada pelos agentes de uma cadeia produtiva (RÖHR et al., 2005). Além disto, o conceito de qualidade é multidimensional. Para Tibério e Cristóvão (1998), a qualidade pode se apresentar por múltiplas dimensões relacionadas aos produtos agroalimentares, destacando-se: higiene e sanidade, nutrição, hedonismo, comércio e caráter simbólico. Considerando-se que a certificação de maçãs é um indicativo importante sobre a qualidade das maçãs, a Tabela 3 apresenta informações sobre como o público consumidor de Santa Maria - RS mostra-se conhecedor dos aspectos referentes à certificação.

O consumidor santa-mariense não considera a certificação como um fator relevante no momento da compra da maçã, pois $51,28 \%$ afirmam não saber o que a mesma é e por outros $42,31 \%$ mostrarem-se indiferentes ao consumo de frutas com algum indicativo de certificação. Por outro lado, nota-se que $28,21 \%$ do público consumidor revelaram ter preferência em comprar e consumir maçãs que passaram por algum processo de certificação. Isso revela que uma parcela considerável dos indivíduos em Santa Maria - RS denota importância, em certa medida, para questões relacionadas à segurança e qualidade da maçã que compra e consume.

Tabela 3 - Conhecimento e preferência quanto à certificação

\begin{tabular}{lcc}
\hline \multicolumn{1}{c}{ Categorias } & $\begin{array}{c}\text { Conhecimento sobre o que é } \\
\text { certificação }(\%)\end{array}$ & $\begin{array}{c}\text { Preferência por comer maçã } \\
\text { certificada (\%) }\end{array}$ \\
\hline Não & 51,28 & 29,48 \\
Sim & 48,72 & 28,21 \\
Indiferente & - & 42,31 \\
\hline
\end{tabular}

Fonte: Elaboração própria, 2019.

Os atores sociais deliberam a qualidade tomando como referência seus interesses e sua capacidade cognitiva e os fatores incidentes no ambiente em que estão inseridos. As diferentes formas de coordenação se referem a diferentes 
princípios para determinar a natureza dos produtos. A especificidade do produto deriva, assim, da realização da variedade de convenções de coordenação entre os atores. Essas características contribuem para a compreensão de como a certificação, enquanto indicativo de qualidade e segurança das maçãs, é vista de forma tão diversa pelo consumidor santa-mariense. Os atributos do bem alimentar são considerados relevantes de acordo com as dimensões cognitivas, valorativas e, até mesmo, emotivas dos indivíduos. A racionalidade dos consumidores, contudo, é limitada pela capacidade cognitiva e pelo próprio contexto dentro do qual estão imersos.

Uma noção de qualidade advém de um processo de negociação para a formação de um quadro valorativo comum, que se torna referência para os atores. Para Vieira et al. (2010), os aspectos que envolvem o ato de consumo são, cada vez mais, importantes, e o papel do consumidor passa a ser fundamental no que se refere à segurança dos alimentos (para a saúde e para o meio ambiente), no controle de produção, certificação de qualidade, garantia de origem (rastreando-se a produção), rotulagem, entre outros. Ademais, para as frutas, a certificação cumpriria os requisitos de mercados nacionais e internacionais e serviria como diferencial aos compradores, que tenderiam a decidir, acompanhado de aspectos qualitativos das frutas em si, a origem da produção, o preço, etc. A fim de evidenciar e contrastar o consumidor santamariense quanto à importância e nível de conhecimento que o mesmo designa para a certificação no momento da compra, a Tabela 4 apresenta tais informações.

Tabela 4 - Frequência de níveis de importância e de conhecimento sobre selo (\%)

\begin{tabular}{lccc}
\hline Níveis & $\begin{array}{c}\text { Importância pelo selo no } \\
\text { produto }\end{array}$ & $\begin{array}{c}\text { Nível de } \\
\text { conhecimento }\end{array}$ & $\begin{array}{c}\text { Preço como fator } \\
\text { relevante }\end{array}$ \\
\hline 1 & 15,38 & 24,36 & 10,9 \\
2 & 8,33 & 19,87 & 8,33 \\
3 & 23,08 & 26,92 & 26,92 \\
4 & 14,1 & 16,67 & 25,64 \\
5 & 39,1 & 12,18 & 28,2 \\
\hline
\end{tabular}

Fonte: Elaboração própria, 2019.

Para Kuneski et al. (2004), a garantia sobre autenticidade de produtos comprados em supermercados é observada pela presença do selo de certificação. Os trabalhos de Lombardi et al. (2004) e Barros e Freitas (2010) discutem a relação entre consumidores e a percepção quanto ao selo, diagnosticando sua importância. Para a realidade do público consumidor santa-mariense, a Tabela 4 retrata informações referentes às frequências para atribuição de níveis de importância para o selo de certificação, o nível de conhecimento sobre o selo e o quão influente é o preço de venda do quilograma da maçã no momento da sua compra.

A importância atribuída para o selo de certificação é alta. A avaliação dos consumidores quanto ao nível de conhecimento individual em relação ao que seja a certificação. Em contraposição com a importância atribuída, o público consumidor concentrou-se nos menores níveis quando relacionado à avaliação do quanto detém de conhecimento sobre o que é certificação. Cerca de $75 \%$ dos consumidores concentraram seus níveis de conhecimento nos valores baixos ao avaliarem o quanto dispõem de informações e conhecimento sobre o que é a certificação nos processos de produção agroalimentar.

O público consumidor afirma não ter um conhecimento amplo sobre o que seja a certificação, ao mesmo tempo que o aponta como algo importante $(39,1 \%$ dos consumidores atribuíram nível de importância máximo). O preço tem um peso relevante na decisão de compra de alimentos. Esse fato levanta a discussão sobre o 
comportamento dos atores sociais quanto à compra, alocação de recursos, racionalidade e visão utilitarista, que denota ao preço um dos principais indicativos de qualidade no mercado. Isso, para o caso da certificação e dos consumidores santamarienses, contrasta com o que Wilkinson (2007) chama atenção para aspectos da importância da noção de qualidade. O preço nos mercados, independentemente do tipo, é um determinante que pode, muitas vezes, sobressair-se a outras questões no momento da decisão de compra. Percebe-se que para os consumidores santamarienses o preço é um quesito importante no momento da compra de maçãs, com $53,84 \%$ dos mesmos atribuem níveis quatro e cinco de importância para ele. Esse fato denota ao preço um dos fatores que conduzem para a compra ou não de maçãs por parte do consumidor do município de Santa Maria - RS.

Howard e Allen (2006) afirmam que os selos de certificação na agricultura informam aos consumidores as características do produto que não são visíveis, aparentes ou capazes de serem verificadas no ato da compra (uso de mão de obra, utilização de venenos etc.). O conhecimento e a importância indicada pelo público consumidor para os selos de certificação nas maçãs no ato da compra são aspectos que denotam características cruciais para o mercado dessa fruta, e também para o conjunto de ações existentes para garantir segurança e controle dos aspectos produtivos. Truninger (2013), em um estudo sobre a relação entre demanda e certificação, revelou que diferentes fatores asseguram uma determinada segurança e confiança do consumidor para produtos agroalimentares. Segundo o autor, a certificação e o rótulo dos produtos são os mais relevantes para os produtos sejam considerados seguros e com características de controle de produção e armazenamento, fidelizando a confiança do consumidor quanto a produtos oriundos da agricultura.

Contrapondo essas relações com a perspectiva do consumidor santamariense para a certificação e a importância apontada para esses processos, foram realizados alguns testes para verificar a existência de relações associativas. Os resultados dos testes permitem avaliar como que as questões individuais e cognitivas dos atores sociais se diferenciam. O teste $t$ aplicou-se a diferenças entre o grupo de consumidores que afirma saber o que é certificação, daqueles que não sabem (Tabela $5)$.

Do total de consumidores entrevistados, $51,61 \%$ afirmaram não saber o que é certificação, em contraponto aos outros $48,38 \%$ que têm conhecimento. Em relação à importância atribuída ao selo de certificação no momento da compra, a média para os consumidores que sabem o que é certificação é superior àqueles que não sabem. Quanto ao predomínio do preço como fator relevante no momento da compra de maçãs, ambos os grupos (sabem e não sabem o que é certificação) atribuíram níveis de importância elevados, de acordo com os dados de média apresentados na Tabela 5.

Os valores associados ao teste de Levene averiguam a homogeneidade das variâncias. Neste caso, observa-se que as variâncias são diferentes, ou seja, não homogêneas, para a variável de importância atribuída ao selo de certificação, uma vez que a significância associada ao teste é inferior a 0,05 (no caso, 0,009). O valor do teste $t$ é de $-5,180$, permitindo que não se aceite a hipótese nula de não existência de diferenças entre o grupo de consumidores que sabem e os que não sabem o que é certificação. Esse fato retrata que os consumidores de Santa Maria - RS que sabem o significado da certificação diferem daqueles que não sabem em relação a importância atribuída ao selo no momento da compra de maçãs.

Para a variável consideração de relevância do preço no momento da compra, não assume-se homogeneidade da variância, pois a significância é 0,836 , superior a 0,05 . $O$ valor do teste $t$ de $-0,472$ permite que se aceite a hipótese nula, permitindo 
que se afirme que não existem diferenças significativamente estatísticas entre o grupo que sabe e o que não sabe o que é certificação, para a média de consideração de relevância dada ao preço. Assim, independentemente de saberem ou não do que se tratam os processos de certificação na produção de maçãs, os consumidores atribuem ao preço um fator determinante para a compra da fruta, tornando-se assim referência de coordenação de mercado. Com base nesse resultado, é possível avaliar que, indiferente das características dos consumidores que sabem e dos que não sabem o que é certificação, o preço torna-se um indicativo conveniente para motivar a compra de maçãs, bem como de determinar a qualidade do produto que está sendo comprado.

Tabela 5 - Estatísticas das variáveis do teste $t$

\begin{tabular}{|c|c|c|c|c|c|c|c|c|}
\hline $\begin{array}{l}\text { Variáveis do } \\
\text { teste }\end{array}$ & $\begin{array}{l}\text { Conheciment } \\
\text { o }\end{array}$ & $\mathrm{N}$ & $\%$ & $\begin{array}{l}\text { Médi } \\
\text { a }\end{array}$ & $\begin{array}{r}\text { Teste de L } \\
\text { Variânc }\end{array}$ & vene & Siq. & $\begin{array}{l}\text { Estat } \\
\dot{t}\end{array}$ \\
\hline \multirow{2}{*}{$\begin{array}{l}\text { Consideraçã } \\
\text { o de } \\
\text { importância }\end{array}$} & Não & $\begin{array}{l}8 \\
0\end{array}$ & $\begin{array}{l}5 \\
2\end{array}$ & 2.96 & Iguais & $\begin{array}{l}7.0 \\
2\end{array}$ & $\begin{array}{l}0.0 \\
0\end{array}$ & $-5,18$ \\
\hline & Sim & $\begin{array}{l}7 \\
5\end{array}$ & $\begin{array}{l}4 \\
8\end{array}$ & 4.05 & $\begin{array}{l}\text { lguais } \\
\text { não } \\
\text { assumida } \\
\text { s }\end{array}$ & & & -5 \\
\hline \multirow{2}{*}{$\begin{array}{l}\text { Preço como } \\
\text { determinant } \\
e\end{array}$} & Não & $\begin{array}{l}8 \\
0\end{array}$ & $\begin{array}{l}5 \\
2\end{array}$ & 3.46 & Iguais & $\begin{array}{l}0.0 \\
4\end{array}$ & $\begin{array}{l}0.8 \\
3\end{array}$ & $-0,47$ \\
\hline & Sim & $\begin{array}{l}7 \\
5\end{array}$ & $\begin{array}{l}4 \\
8\end{array}$ & 3.56 & $\begin{array}{l}\text { lguais } \\
\text { não } \\
\text { assumida } \\
\text { s }\end{array}$ & & & $-0,47$ \\
\hline
\end{tabular}

Fonte: Elaboração própria, 2019.

O teste de Qui-Quadrado $\left(X^{2}\right)$, aplicado para verificar a associação entre o fato dos consumidores terem ou não conhecimento acerca dos processos de certificação e terem preferência por comprar maçãs com algum indicativo de certificação. A Tabela 6 mostra informações sobre a distribuição das respostas apontadas quanto à preferência por adquirir maçãs com certificação e o conhecimento sobre o que se trata.

Observa-se a forma como os consumidores distribuem-se quanto ao conhecimento ou não sobre o que é a certificação e a preferência pela compra de maçãs com seu indicativo. Verifica-se que, dentre os consumidores que afirmam não ter conhecimento sobre o que são os processos de certificação agroalimentares, a maior parte não revela preferir adquirir maçãs ou diz-se ser indiferente ao fato de a maçã comprada possuir ou não algum indicativo de certificação, representando $86,75 \%$ do total. É interessante notar que, por outro lado, daqueles consumidores que afirmam saber o que é certificação, mais da metade (53,33\%) mostram-se indiferentes quanto sua preferência em comprar maçãs que apresentam algum indicativo de certificação. 
Tabela 6 - Preferência pela compra de maçãs certificadas e nível de conhecimento

\begin{tabular}{|c|c|c|c|}
\hline Item & \multicolumn{3}{|c|}{ Conhecimento sobre o que é certificação } \\
\hline \multirow{4}{*}{$\begin{array}{l}\text { Preferência por comprar maçã com } \\
\text { certificação }\end{array}$} & & Não & Sim \\
\hline & Não & 43 & 2 \\
\hline & Sim & 11 & 33 \\
\hline & Indiferente & 26 & 40 \\
\hline Total & & 80 & 75 \\
\hline & Valor & \multicolumn{2}{|c|}{ Significância } \\
\hline Qui-quadrado de Pearson & 51.217 & \multicolumn{2}{|c|}{0.00} \\
\hline Razão de verossimilhança & 60.362 & \multicolumn{2}{|c|}{0.00} \\
\hline
\end{tabular}

Fonte: Elaboração própria, 2019.

O fato dos indivíduos afirmarem que possuem conhecimento sobre o que são os processos de certificação, sem levar em conta o nível e o discernimento desse conhecimento, mostra a indiferença por parte do próprio consumidor em revelar preferências em comprar agroalimentos certificados. A significância associada ao teste de Qui-Quadrado $\left(X^{2}\right)$ é menor que 0,05 para a preferência por comprar maçãs com certificação relacionada com o conhecimento ou não acerca do que é a certificação no entendimento dos santa-marienses. Com isso, evidencia-se que a associação observada entre saber o que é certificação e a preferência por comprar maçãs com indicativo de certificação é estatisticamente significativa, em que mudanças no fato do consumidor ter ou não conhecimento sobre o que é a certificação tem relação associativa com o fato de estes revelarem ter preferência em comprar maçãs certificadas.

\section{CONSIDERAÇÕES FINAIS}

As discussões sobre a qualidade nos sistemas agroalimentares avançaram na economia, ao apresentarem respostas para como os agentes econômicos consideram a qualidade (e os atributos qualificáveis) de bens e serviços, para além de questões básicas de operacionalização de mercado, como o preço. Buscamos estabelecer o vínculo entre os quesitos pertinentes à EC para compreender: (i) como a preocupação com a qualidade e segurança de alimentos promoveu mudanças institucionais nos sistemas de exigências comerciais a nível internacional, em que se destacam os sistemas de certificação, e; (ii) demonstrar a percepção do consumidor, discutindo-se as questões pertinentes ao comportamento individual no mercado de maçãs e sua relação com a certificação e qualidade foram discutidas e analisadas.

Ao afetar distintas etapas da cadeia produtiva, os processos de certificação exigem do produtor padrões que sejam reconhecidos em escala maior daquela de inserção produtiva. É fato que tais exigências garantem ao produtor e ao seu sistema agroalimentar o acesso a mercados, a agregação de valor, o reconhecimento de características culturais (tradicionais) e até regionais. Contudo, a adoção de processos de certificação na produção parte do pressuposto de que o consumidor compreende, valoriza e diferencia o alimento que atenda tais requisitos representado pelo selo de certificação no momento da compra. O selo, em primeira instância, denota características que estão por trás do produto, ou seja, que não podem ser palpáveis no momento da compra. Assim, os sistemas de certificação 
induzem mudanças nos aspectos produtivos de determinado bem agroalimentar que condicionam, em consequência, a oferta disponibilizada para o consumidor final.

Os consumidores analisados apresentam características socioeconômicas heterogêneas. O contexto de inserção social dos consumidores é uma característica importante que denota a dimensão cognitiva o conhecimento de informações relacionadas à qualidade de um determinado bem. A EC destaca dimensões cognitivas, valorativas e emotivas como fatores condicionantes para a formação de opinião e avaliação de um determinado bem. Diante de tais características, constatouse que os consumidores não primam pelas informações sobre segurança transmitida e a eles apresentadas nas frutas através de selos de certificação.

Da amostra representativa analisada, aproximadamente metade afirmou saber o que é certificação, havendo pessoas que, além de não saberem seu significado, não a consideram relevantes no momento da compra, dando primazia para outros aspectos, como o preço da fruta. A ênfase para o preço sinaliza que os consumidores fazem uso do que é apontado pelo mercado para compor suas opções e, consequentemente, decisões no momento da compra. Considerando apenas este fato, o quesito regulador básico do mercado para a economia neoclássica torna-se verdadeiro para a realidade empírica estudada. As características basilares da Economia das Convenções, contudo, vem ao encontro dos limites impostos pelo fator preço como regulador e transmissor de informações relativas à qualidade para bens e serviços.

O valor atribuído pelos atores sociais ao acessar mercados é construído socialmente e manifesta-se na falta de uma compreensão que seja geral em relação ao valor. A diversidade social e os diferentes contextos de inserção dos atores os diferenciam quanto aos quesitos de qualidade que são valorados. Diante disto, a perspectiva teórica das convenções considera que a falta de informações necessárias para otimizar as escolhas passa a ser avaliada como as diversas possibilidades de atributos dos bens e diferentes que orientam o processo decisório dos atores sociais.

Diante dos resultados observados no estudo, o pressuposto de que a relação entre consumidor e produto se apresenta por uma demanda de alimentos que sejam considerados mais seguros ou que garantam o direito de as pessoas terem acesso à alimentação digna e de qualidade não se confirma com efetividade. A constante normatização dos sistemas agroalimentares, com regras e diretrizes produtivas ocorre, em sentido mais amplo, em complacência com a complexidade dos programas de certificação, que teriam por objetivo representar essa segurança e os quesitos de qualidade. A certificação, entretanto, é vista como um instrumento regulador de mercado, permitindo que se atenda a exigências internacionais de controle de qualidade e segurança dos alimentos. As informações conhecidas pelos consumidores, quanto à própria certificação e as demais características do produto, poderiam ser fatores condicionantes para o momento da compra, contudo esse fato que não se revelou para a realidade santa-mariense.

Enquanto limite do presente estudo, cita-se o uso da EC como arcabouço teórico para colaborar com a compreensão do comportamento do consumidor, frente à certificação e aos aspectos de qualidade de alimentos. As distintas formas de coordenação econômica pelos atores sociais podem ser determinadas por vários fatores, tendo assim significados inscritos de variadas formas, bem como seus usos e suas trajetórias. Somente pela análise destas trajetórias poder-se-ia interpretar as transações e os aspectos qualitativos que são considerados no momento das trocas nos mercados agroalimentares.

Considera-se, por fim, que cada uma destas formas de coordenação se refere a diferentes princípios para determinar a natureza dos produtos, sua qualidade. A especificidade do produto deriva, então, da realização da variedade de convenções 
de coordenação entre os atores. O presente estudo buscou estabelecer a relação entre as mudanças normativas dos sistemas agroalimentares, inserindo o caso da maçã e dos processos de certificação da fruta frente ao consumidor local, buscando verificar como se dão os modos de coordenação, e na diversidade de referenciais de qualidade.

\section{REFERÊNCIAS}

ALLAIRE, G.; BOYER, R. (Org.). Regulation et conventions dans l'agriculture et les IAA. In: La grande transformation de l'agricultura. Paris: INRA/Economica, 1995. p. 9-32.

ALPHANDÉRY, P. et. al. Normaliser au nom du développement durable: dispositifs, savoirs, politiques. Paris: Editora Quae, 2012.

AMBROSINI, L. B; OLIVEIRA, C. A. O. Indicação geográfica para frutas: critérios de concessão e objetivos, uma análise comparativa de casos europeus e brasileiros. Extensão Rural, Santa Maria, v. 24, n. 3, p. 24-43, nov. 2017. Disponível em: https://periodicos.ufsm.br/extensaorural/article/view/26227/pdf. Acesso em: 13 out. 2019.

BARBETA, P. A. Estatística aplicada às ciências sociais. Florianópolis: UFSC, 7. ed. 2008. 345 p.

BARROS, A. F.; VARELLA, M. D. A nova tendência mundial de segurança alimentar e o sistema de certificações. Territórios em movimento: cultura e identidade brasileira. Informações Econômicas. São Paulo, v. 33, n. 7, jul. 2002.

BRASIL. Ministério da Agricultura, Pecuária e Abastecimento. Registro de Estabelecimento Exportador. 2014. Disponível em http://www.agricultura.gov.br/vegetal/registros-autorizacoes/registro/registroestabelecimento-exportador. Acesso em: 10 set. 2015.

CODEX ALIMENTARIUS. Definitions. 2007. Disponível em: http://www.codexalimentarius.net/web/index_en.jsp. Acesso em: 1 fev. 2015.

CALDENTEY, P.; GOMEZ, A. C. Productos agroalimentarios típicos y territorio: alimentos con historia, alimentos de calidad. Distribución y Consumo, p. 69-73. Madrid: Mercasa, 1997.

COMUNELLO, F. J. Produto orgânico de produção agroecológica: a sensibilidade jurídica dos produtores agroecológicos. Extensão Rural, Santa Maria, v. 20, n. 1, p. 69-80, jan./abr. 2013. Disponível em: https://periodicos.ufsm.br/extensaorural/article/view/8588/5211. Acesso em: 13 out. 2019.

COSTA, M. C. et. al. Non conventional technologies and impact on consumer behavior. Trends in Food Science \& Technology. London, v. 11, n. 4-5, p. 188-193, 2000. 
DE SAINTE-MARIE, C. et al. La construction sociale de la qualité. In: NICOLAS, F.; VALCESCHINI, E. Agro-alimentaire: une économie de la qualité. Paris: INRA/Economica, 1995.

DÖRR, A. C. et al. Análise econômica da certificação na cadeia de citros: estudo de caso de uma cooperativa no Vale do Caí-RS. Extensão Rural, Santa Maria, v.17, n. 19, p. 75-92, jan./jun. 2010. Disponível em: https://periodicos.ufsm.br/extensaorural/article/view/5515/3266. Acesso em: 13 out. 2019.

EYMARD-DUVERNAY, F. Conventions de qualité et formes de coordination. Revue Economique, França, v. 40, n. 2, p. 329-359, 1989.

FORNARZIER, A. Mudança institucional no ambiente produtivo da maçã com a adoção da Produção Integrada de Frutas (PIF). 2010. 120 f. Dissertação (Mestrado em Agronegócios) - Centro de Estudos e Pesquisas em Agronegócios, Universidade Federal do Rio Grande do Sul, Porto Alegre, 2010.

FOUILLEUX E. Vers une agriculture durable? Normes volontaires et privatisation de la régulation. In: JACQUET, P.; PACHAURI, R.; TUBIANA, L. (Eds.). Développement, alimentation, environnement: changer l'agriculture? Paris: Armand Colin, 2012. p. 301-310.

GIL, A. C. Métodos e técnicas de pesquisa social. 4 ed. São Paulo: Atlas, 1995.

GOMEZ, P. Y. Qualité et théorie des conventions. Paris: Collection Recherche en Gestion/Economica. 1994

GUÉNEAU S. Certification as a new private global forest governance system: the regulatory potential of the Forest Stewardship Council. In: FÖSTER, T.; PETERS, A. (Orgs.). Non-State Actors in Standard Setting Cambridge. Cambridge: Cambridge University, 2009.

HENSON, S.; JAFFEE, S. Developing Country Responses to the Enhancement of Food Safety Standards. In: GROTE, U.; BASU, A.K.; CHAU, N.H. (Eds). New Frontiers in Environmental and Social Labeling. Williamsburg: Physica-Verlag, 2007. pg. 193-220.

HODGSON, G. Economia e Instituições: manifesto por uma economia institucionalista moderna, Oeiras: Celta, 1994.

HOWARD, P. H.; ALLEN, P. Beyond organic: consumer interest in new labelling schemes in the Central Coast of California. International Journal of Consumer Studies. Whashington, v. 30, n. 5, p. $439-451,2006$.

INSTITUTO BRASILEIRO DE GEOGRAFIA E ESTATÍSTICA - IBGE. IBGE Cidades - Santa Maria. 2018. Disponível em: http://cidades.ibge.gov.br/. Acesso em: 15 ago. 2018.

INSTITUTO BRASILEIRO DE GEOGRAFIA E ESTATÍSTICA - IBGE. Levantamento sistemático da produção agrícola. 2010. Disponível em: 
ftp://ftp.ibge.gov.br/Producao_Agricola/Levantamento_Sistematico_da_Producao_Ag ricola_[mensal]/Fasciculo/2012/lspa_201202.pdf. Acesso em: 30 out. 2017.

KUNESKI, M.; CAZELLA, A. A.; KARAM, K. F. Apoio a consumidores de produtos agroecológicos na região da grande Florianópolis. Revista Eletrônica de Extensão. Florianópolis, v.1, n.1, 2004.

MALAFAIA, G. C.; BARCELLOS, J. O. J.; AZEVEDO, D. B. Motivações para a criação de convenções de qualidade na cadeia da carne bovina gaúcha. Revista CCEI, Bage, v.14, n.25, p.157 - 172 - mar., 2010.

MARESCOTTI, A. Marketing channels, quality hallmarks and the theory of conventions. In: SYLVANDER, B.; BARJOLLE, D.; ARFINI, F. (Eds.). The socioeconomics of origin labelled products in agrofood supply chains: spatial, institutional and co-ordination aspects. Paris: INRA, 2000.

NIEDERLE, P. A. Economia das Convenções: subsídios para uma sociologia das instituições econômicas. Ensaios FEE, Porto Alegre, v. 34, n. 2, p. 439-470, dez. 2013.

OLIVEIRA, L. A. A importância das normas internacionais para o comércio da fruticultura brasileira. 2005. 168 f. Dissertação (Mestrado em Economia) - Escola Superior de Agricultura Luiz de Queiroz, Universidade de São Paulo, Piracicaba, 2005.

PERETTI, A. A. R.; ARAÚJO, W. M. C. Abrangência do requisito segurança em certificados de qualidade da cadeia produtiva de alimentos no Brasil. Revista Gest. Prod. São Carlos, v. 17, n. 1, p. 35-49, 2010.

ROHR, A. Food quality and safety-consumer perception and public health concern. Food Control. Guildford, v. 16, n. 8, p. 649-655, out. 2005.

SYLVANDER, B. Conventions de qualité, marchés et institution: les cas des produits de qualité spécifique. In: NICOLAS, F.; VALCESCHINI, E. Agro-alimentaire: une économie de la qualité, Paris: INRA, 1995.

THÉVENOT, L. Organized complexity: conventions of coordination and the composition of economic arrangements. European Journal of Social Theory, London, v. 4, n. 4, p. 405-425, 2001.

TIBÉRIO, L.; CRISTÓVÃO, A. A origem como factor de qualidade dos produtos agrícolas e agro-alimentares: o caso dos produtos beneficiários da Protecção Comunitária Denominação de Origem Protegida. In: Jornadas Interprofissionais agroalimentares, 1998. Miranda. Anais... Miranda: DES/UTAD, 1998.

TIBÉRIO, L.; CRISTÓVÃO, A. A definição da qualidade em fileiras de produtos qualificados: uma aplicação do modelo CQFD e da teoria das convenções. Revista de Economia Agrícola, São Paulo, v. 59, n. 2, p. 99-114, jul./dez. 2012

TRUNINGER, M. O campo vem à cidade: Agricultura Biológica, Mercado e Consumo Sustentável. Lisboa: Imprensa de Ciências Sociais. 2010. 
VAN RIJSWIJK, W.; FREWER, L. J.; MENOZZI, D.; FAIOLI, G. Consumer perceptions of traceability: A cross-national comparison of the associated benefits. Food Quality and Preference. Barking, v. 19, n. 5, p. 452-464, 2008.

VIEIRA, A. C. P.; BUAINAIN, A. M.; SPERS, E. E. A segurança do alimento e a necessidade da informação aos consumidores. Cadernos de Direito. São Paulo, v.10, n. 19, jul./dez. 2010.

WILKINSON, J. Fair Trade: dynamics and dilemmas of a market oriented global social movement. Journal of Consumer Policy. Washington, v. 30, p. 219-239, 2007. 